Article

\title{
On the Absolute Stereochemistry of Tolterodine: A Circular Dichroism Study
}

\author{
Marcin Górecki ${ }^{1}$ 2@ , Valerio Zullo ${ }^{1}$, Anna Iuliano ${ }^{1}$ and Gennaro Pescitelli ${ }^{1, *(\mathbb{C})}$ \\ 1 Dipartimento di Chimica e Chimica Industriale, Università di Pisa, Via Moruzzi 13, 56124 Pisa, Italy; \\ marcin.gorecki@icho.edu.pl (M.G.); valeriozullo@hotmail.it (V.Z.); anna.iuliano@unipi.it (A.I.) \\ 2 Institute of Organic Chemistry, Polish Academy of Sciences, Kasprzaka 44/52 St., 01-224 Warsaw, Poland \\ * Correspondence: gennaro.pescitelli@unipi.it
}

Received: 28 December 2018; Accepted: 22 January 2019; Published: 26 January 2019

\begin{abstract}
Tolterodine (1) is a potent muscarinic receptor antagonist used in the treatment of overactive urinary bladder $(\mathrm{OAB})$ syndrome. Tolterodine is chiral and it was patented, and is currently marketed, as the L-tartrate salt of the $(R)$-enantiomer. However, the existing literature does not offer an ultimate proof of a stereoselective mode of action of $\mathbf{1}$. A second open stereochemical issue concerns the absolute configuration (AC) of $\mathbf{1}$. Neither the original patents nor subsequent studies have established the AC of $\mathbf{1}$ in an unambiguous way, although the AC of the L-tartrate salt of $\mathbf{1}$ was assigned by $\mathrm{X}$-ray diffractometry. Finally, neither electronic nor vibrational circular dichroism (ECD and VCD) spectra of $\mathbf{1}$ are reported so far. We performed a thorough ECD/VCD study of $\mathbf{1}$ in different solvents and at variable temperatures. Solvent and temperature dependence highlighted the existence of moderate flexibility which was confirmed by molecular modelling. ECD calculations with time-dependent density functional theory (TDDFT) accurately reproduced the experimental spectra and allowed us to confirm the AC of $\mathbf{1}$ in an independent way.
\end{abstract}

Keywords: absolute configuration; drug enantiomers; circular dichroism calculations; conformational analysis; variable-temperature CD; solvent dependent CD

\section{Introduction}

Tolterodine (1, Figure 1) is a potent muscarinic receptor antagonist used in the treatment of overactive urinary bladder (OAB) syndrome, which causes incontinence and other symptoms [1-3]. Compared to other antimuscarinic drugs, it benefits from better tolerability and diminished side effects. Tolterodine (1) contains a single chirality center and may therefore exist as two different enantiomers. In general, the two enantiomers of a chiral substance show different pharmacology, ADME, and toxicology [4]. Tolterodine is marketed as the L-tartrate salt of the $(R)$-enantiomer (2), the form patented by Jönsson et al. in 1989 [5] and approved by FDA in 1998 [6]. Salt 2 is commonly named tolterodine tartrate [1], although a more correct name would be tolterodinium hydrogen tartrate. In the original patent, salt (+)-2 was reported to have the same calcium antagonistic effect as the enantiomeric salt (-)-2 and racemic tolterodine (1). The toxicities of the two enantiomers of salt 2 were also the same. Only for the anticholinergic activity, was (+)-2 found to be 100 times more active than (-)-2. Very surprisingly, however, rac-1 was as active as (+)-2 as an anticholinergic. Reported $\mathrm{IC}_{50}$ values were $1.5 \times 10^{-2} \mu \mathrm{M}$ for $r a c-1,1.3 \times 10^{-2} \mu \mathrm{M}$ for $(+)-2$, and $1.3 \mu \mathrm{M}$ for $(-)-2$. These data do not offer sufficient proof of a stereoselective mode of action of tolterodine, although they still remain the only reported data about the (possible) drug stereoselectivity. To the best of our knowledge, in fact, the superiority of the $(R)$-enantiomer over the $(S)$ - one for treating OAB syndrome has not been further proved. Almost all subsequent studies concerned the drug only in its (+)-2 form [7,8]. Lately, (S)-tolterodine was also patented against urinary disorders [9]. When both enantiomers were 
tested for other types of activity, either no significant difference was found [10,11], or (S)-tolterodine displayed stronger activity $[12,13]$. Other antimuscarinic drugs like oxybutynin have an established enantioselective mode of action [14]. Because of the importance of tolterodine, it is not surprising that several enantioselective syntheses and enantiomer separations are reported to date, mainly to substantiate some new chiral auxiliary or catalyst [1]. According to our literature survey, however, obtaining enantiopure tolterodine may not be worth these efforts.<smiles>Cc1ccc(O)c(C(CCN(C(C)C)C(C)C)c2ccccc2)c1</smiles>

Tolterodine (1)<smiles>CCCCCCCCCCCC(=O)[C@@H](O)[C@@H](O)C(=O)[O-]</smiles>

Figure 1. Structures of (R)-tolterodine (1), its hydrogen L-tartrate salt 2, and precursor 3.

This is not the only open issue concerning the stereochemistry of tolterodine (1), the other one relates to its absolute configuration (AC). In the 1989 patent by Jönsson et al. [5], it was reported that the crystallization of $r a c-1$ with L-(+)-tartaric acid in ethanol afforded (+)-2 salt with $[\alpha]_{546}^{25}+36.0$ ( $c$ unknown), whereas the same procedure with D-(-)-tartaric acid afforded (-)-2 salt with $[\alpha]_{546}^{25}$ - 35.8. The reported elemental analysis clarifies that the obtained salts were hydrogen tartrates, i.e., with a 1:1 1 to tartrate proportion as reported in Figure 1 for $\mathbf{2}$. However, no correlation between the $(+) /(-)$ sign of salt 2 and the AC of its component 1 was given. In a later patent by Gage and Cabaj [15], the same crystallization procedure of $r a c-1$ with L-(+)-tartaric acid in ethanol was repeated, affording (+)-2 salt with $[\alpha]_{D}^{25}+27.4\left(c 1 \%\right.$, methanol) and a m.p. of $210-211^{\circ} \mathrm{C}$. This patent mentions for the first time the AC of $\mathbf{1}$ : the "racemic compound [rac-1] is later resolved in the conversion of tolterodine to $(R)$-tolterodine L-tartrate". Very surprisingly, however, no details are given on how the $(R)$-configuration was established [15]. The two mentioned patents are often quoted as the proof of the $(R)$-configuration of component $\mathbf{1}$ in the (+)-2 salt; from what said above, however, it is clear that such a claim is inappropriate. The first and only proof, to the best of our knowledge, of the AC of tolterodine was provided in 2005 by the X-ray determination of its salt 2 by Košutić-Hulita and Žegarac [16]. The species investigated was correctly named tolterodinium $(2 R, 3 R)-(+)$-hydrogen tartrate (2); we note, however, that the " $(2 R, 3 R)-(+)$ " notation refers to the tartrate component of 2 , not to the salt itself. Using L-tartaric acid as internal reference, the AC of component 1 in the drug $\mathbf{2}$ was unambiguously identified as $(R)$. Surprisingly enough, this paper has been quoted only five times to date, but never as the proof of the AC of tolterodine [1,17-20]. As a matter of fact, the correlation between the species investigated by X-ray and those described in the patents is unsure. Košutić-Hulita and Žegarac stated that the compound was prepared according to Gage and Cabaj's procedure, however, 1,2-propylene carbonate was used as crystallization solvent instead of ethanol, the m.p. of the product was reported as $216^{\circ} \mathrm{C}$ and, most importantly, the optical rotation (OR) of the salt 2 was not measured.

An unambiguous assignment of the AC of tolterodine (1) should obviously come from one of the several enantiospecific syntheses that have appeared in the literature [1]. The first enantiospecific synthesis, patented by Piccolo et al. in 2005 [21], used 6-methyl-4-phenylchroman-2-one (3) (Figure 1) 
as the stereodefinite intermediate. According to this patent, which is also often quoted as proof of the AC of tolterodine, $(S)-(-)-3$ was converted into $(S)-(-)-1$ by an enantiospecific route. The procedure was replicated by the same authors two years later in a paper, which also provided the first explicit correlation between the OR sign of 1 and 2 [22]. Chromanone 3 is a common intermediate in the route to 1 [23-26], although with unexpected implications. In fact, in a later report by Chen et al., the correlation was between $(R)-(-)-3$ and $(R)-(+)-\mathbf{1}[23]$, that is, the AC of $\mathbf{3}$ was reversed with respect to Piccolo et al. [21,22]. A literature search on the reported OR values for 6-methyl-4-phenylchroman-2-one (3) confirms this inconsistency. Available OR data for $(R)-3$ in chloroform are negative and span from $[\alpha]_{\mathrm{D}}^{20}-2.2(c 0.3)$ to $[\alpha]_{\mathrm{D}}^{20}-6.2$ (c 1) [23,26-29]. A very large positive value was however obtained in dichloromethane $[\alpha]_{\mathrm{D}}^{20}+36\left(c\right.$ 1) [24]. For $(S)-3$, Piccolo et al. reported a negative $[\alpha]_{\mathrm{D}}^{20}-2.8(c 1.44$, chloroform) [21,22]. In none of the syntheses of $\mathbf{1}$ involving $\mathbf{3}$ as intermediate [23-26], was the AC of this latter assigned independently from that of $\mathbf{1}$. Since the AC of $\mathbf{1}$ was (incorrectly) given for established in the aforementioned patents $[5,15,21]$, it is logical that the reported enantioselective syntheses of $(R)-(+)-\mathbf{1}$ were not further concerned with the stereochemical assignment [1].

From the above survey it appears that from the stereochemical point of view tolterodine (1) still has several aspects of interest. Additionally, we were surprised to find that no circular dichroism investigation of $\mathbf{1}$ has appeared to date. In 2018, Kirkpatrick et al. reported the electronic circular dichroism (ECD) data of tolterodine tartrate in a study about HPLC-ECD analysis of various drugs [30,31]. Very recently, some of us prepared tolterodine (+)-1 with high enantiomeric purity (96\%), starting from the optically active ethyl 3-phenyl-3-(2-hydroxy-5-methyl)phenylpropanoate (ee 96\%) [32]. We took then the chance for a chiroptical investigation of 1 by means of electronic and vibrational CD (ECD and VCD), from both an experimental and computational point of view.

\section{Results and Discussion}

\subsection{Sample Preparation}

Tolterodine (+)-1 was synthesized as described in Scheme 1. The enantioselective step was the Rh-catalyzed conjugate addition of phenylboronic acid to the ethyl3-arylpropenoate 6, in turn prepared in two steps from 5-methylsalicylaldehyde (4). This reaction, promoted by a deoxycholic-based binaphthyl phosphite, used as chiral ligand of $\mathrm{Rh}(\mathrm{I})$, gave optically active 7 with $96 \%$ ee. Hydrolysis of the ester group and reaction of the resulting carboxylic acid with diisopropyl amine in the presence of EDC, afforded, after chromatographic purification of the crude, the pure amide 9. Reduction of the amide and hydrogenolysis of the benzyl protecting group gave (+)-tolterodine 1, whose optical rotation was $[\alpha]_{\mathrm{D}}^{20}+24.9(c 1.50, \mathrm{MeOH})$ [Lit. value: [22] $[\alpha]_{\mathrm{D}}^{20}-23.0(c 1.5, \mathrm{MeOH})$ for $(S)$-tolterodine].

\subsection{Experimental ECD Spectra}

Tolterodine (1) contains two aromatic chromophores attached to the same carbon atom, which is also the only chirality center. The chromophores are a $p$-methylphenol and a phenyl chromophore $[33,34]$. ECD spectra of $(+)-\mathbf{1}$ were recorded in five different solvents, methylcyclohexane $(\mathrm{MCH})$, chloroform, acetonitrile $(\mathrm{ACN})$, methanol $(\mathrm{MeOH})$ and water, and are shown in Figure 2. 


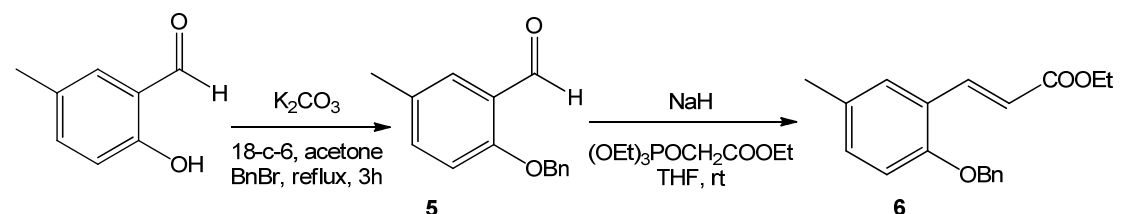

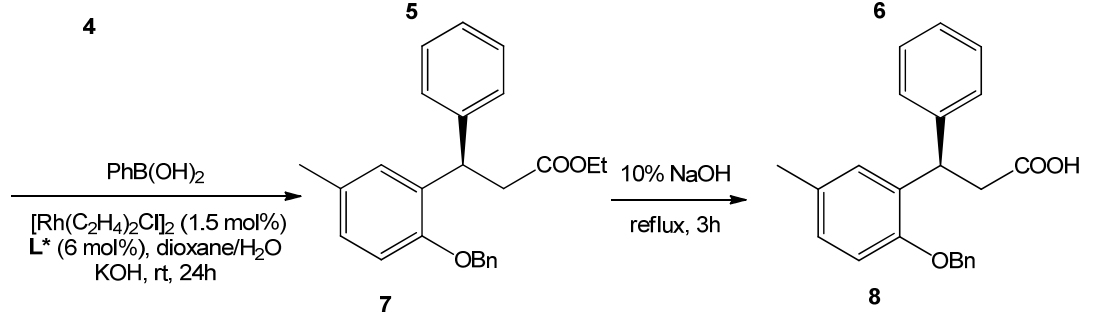

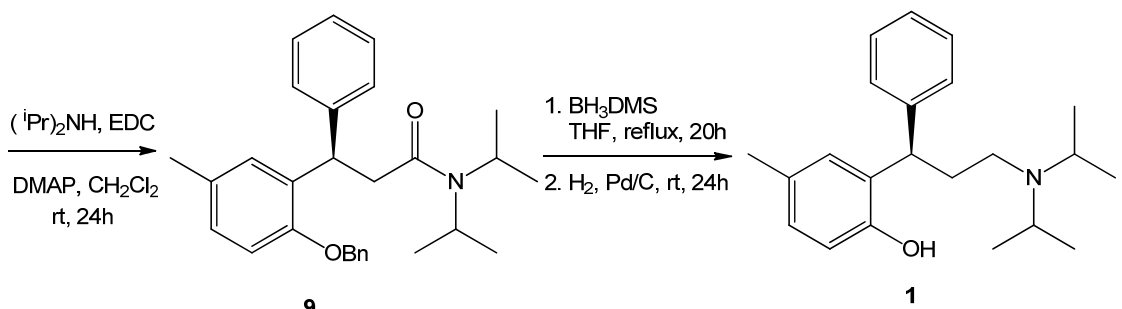<smiles>CC(=O)CC[C@@H](C)[C@H]1CCC2C3CCC4C[C@@H](C(C)=O)CC[C@]4(C)C3C[C@H](Op3oc4ccc5ccccc5c4c4c(ccc5ccccc54)o3)[C@@]21C</smiles>

Scheme 1. Enantioselective route to $(R)-(+)$-tolterodine 1.
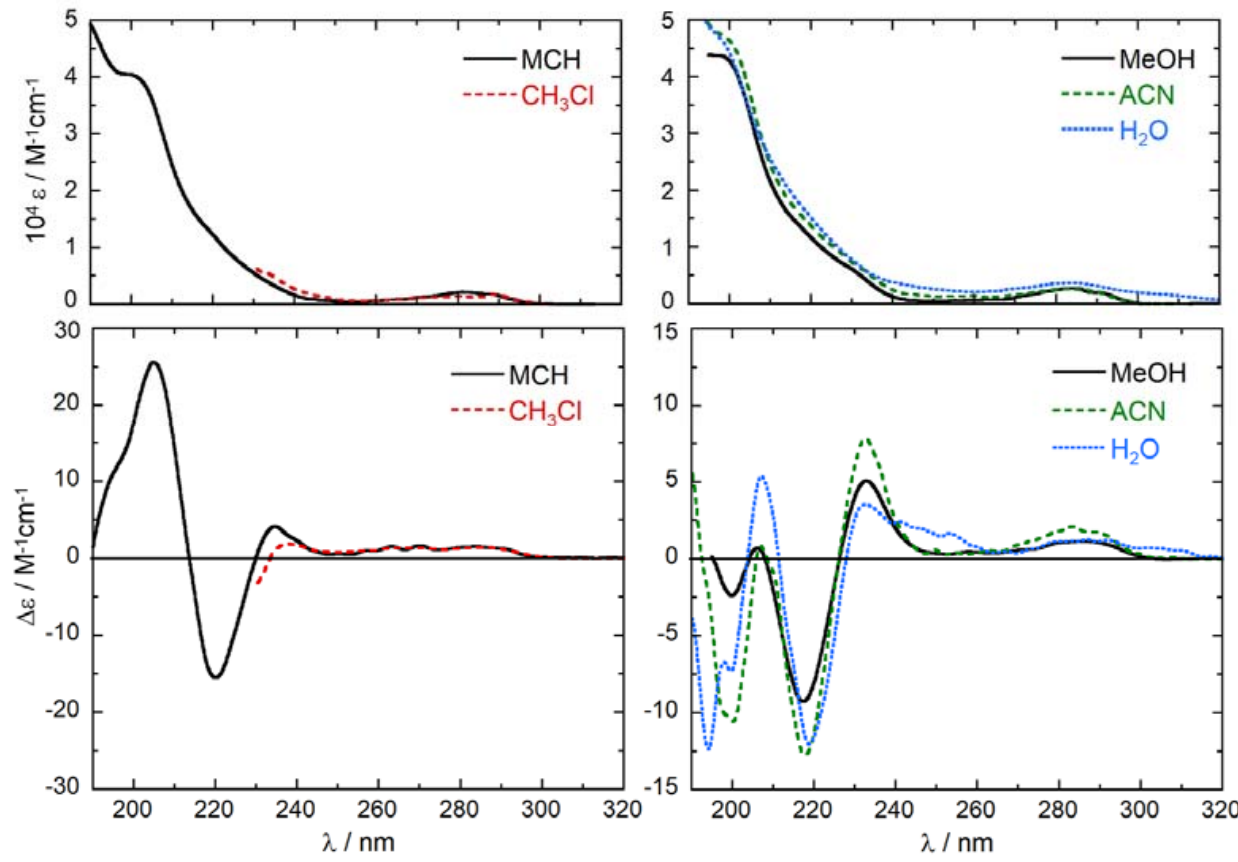

Figure 2. Absorption (top) and ECD spectra (bottom) of (R)-tolterodine (1) measured in different solvents. Concentration $1.67 \times 10^{-4} \mathrm{M}$, cell path length $0.1 \mathrm{~cm}$. 
They all display a weak and structured positive band between 260 and $300 \mathrm{~nm}\left(\Delta \varepsilon=+1-2 \mathrm{M}^{-1}\right.$ $\left.\mathrm{cm}^{-1}\right)$, associated with a weak absorption in the same region $\left(\varepsilon=2000-3000 \mathrm{M}^{-1} \mathrm{~cm}^{-1}\right)$. These bands are allied with the ${ }^{1} \mathrm{~L}_{\mathrm{b}}$ transitions of the substituted phenol and phenyl chromophores, occurring respectively at longer and shorter wavelength [35,36]. The presence of a long-wavelength tail in $\mathrm{H}_{2} \mathrm{O}$ lets us suspect that some aggregation occurs in this solvent even at the low concentration employed. The combination of ${ }^{1} \mathrm{~L}_{\mathrm{a}}$ transitions of the two chromophores is responsible for the absorption and ECD bands in the 210-240 $\mathrm{nm}$ region [35,36]. All spectra feature a moderate positive ECD band around $235 \mathrm{~nm}\left(\Delta \varepsilon=+4-8 \mathrm{M}^{-1} \mathrm{~cm}^{-1}\right)$ and a more intense negative band around $220 \mathrm{~nm}\left(\Delta \varepsilon=-10-15 \mathrm{M}^{-1}\right.$ $\left.\mathrm{cm}^{-1}\right)$. The intensity and wavelength of both bands are affected by the solvent, but there is no regular trend following the solvent polarity. For the first positive band, the wavelength maximum decreases in the order $\mathrm{CHCl}_{3}>\mathrm{MCH}>\mathrm{MeOH} \sim \mathrm{H}_{2} \mathrm{O}>\mathrm{ACN}$; for the second negative band, the wavelength order is $\mathrm{MCH}>\mathrm{H}_{2} \mathrm{O}>\mathrm{ACN}>\mathrm{MeOH}$ (not recorded in $\mathrm{CHCl}_{3}$ ). For the first band, the intensity order is $\mathrm{ACN}>\mathrm{MeOH}>\mathrm{MCH}>\mathrm{H}_{2} \mathrm{O}>\mathrm{CHCl}_{3}$; for the second band, the intensity order is $\mathrm{MCH}>\mathrm{ACN}$ $>\mathrm{H}_{2} \mathrm{O}>\mathrm{MeOH}$. At shorter wavelength, where ${ }^{1} \mathrm{~B}_{\mathrm{b}}$ transitions occur, UV spectra are quite similar in all solvents but ECD spectra differ a lot. The ECD spectrum in $\mathrm{MCH}$ shows a strong positive band at $205 \mathrm{~nm}\left(\Delta \varepsilon=+25.8 \mathrm{M}^{-1} \mathrm{~cm}^{-1}\right)$ with a short-wavelength shoulder, followed by a negative tail below $190 \mathrm{~nm}$. The ECD spectrum in $\mathrm{H}_{2} \mathrm{O}$ shows a positive band at $207 \mathrm{~nm}\left(\Delta \varepsilon=+5.6 \mathrm{M}^{-1} \mathrm{~cm}^{-1}\right)$ and three negative bands in the 190-200 region, the most intense of which is observed at $194 \mathrm{~nm}(\Delta \varepsilon=-12.1$ $\left.\mathrm{M}^{-1} \mathrm{~cm}^{-1}\right)$. The ECD spectrum in ACN is very weak around $205 \mathrm{~nm}$ but shows a moderately strong negative band at $199 \mathrm{~nm}\left(\Delta \varepsilon=-10.7 \mathrm{M}^{-1} \mathrm{~cm}^{-1}\right)$ followed by a positive signal around $190 \mathrm{~nm}$. Finally, the ECD spectrum in $\mathrm{MeOH}$ is weak below $210 \mathrm{~nm}$. The relatively large variance of ECD spectra with the solvent, and the absence of a clear trend following the solvent polarity may only be justified with the occurrence of solvent-dependent conformational equilibria, favored by the molecular flexibility of 1. It is useful to recall that ECD spectra depend not only on the absolute configuration, but also on the molecular conformation [37,38].

To further investigate the impact of the conformational freedom on the ECD spectra, variable temperature ECD (VT-ECD) spectra were recorded in $\mathrm{MeOH}$ and in $\mathrm{MCH}$ in the range from -80 to $+20{ }^{\circ} \mathrm{C}(193-293 \mathrm{~K})$, shown in Figure 3. The overall spectral shape is retained upon lowering the temperature in both solvents. The sign of the three major bands in the range $210-300 \mathrm{~nm}$ is preserved, accompanied by an intensity increase. For the spectra in $\mathrm{MeOH}$, the increase is regular and more pronounced, and does not reach convergence at the lowest temperature used. The two stronger bands at 215 and $235 \mathrm{~nm}$ almost double their strength when passing from $20{ }^{\circ} \mathrm{C}$ to $-80{ }^{\circ} \mathrm{C}(273 \mathrm{~K}$ to $193 \mathrm{~K})$. In the same temperature range, the spectra in $\mathrm{MCH}$ experience a smaller intensity increase (25-30\%) for both 220 and $235 \mathrm{~nm}$ bands. The trends observed in both solvents clearly indicate a fluxional situation at room temperature-especially in $\mathrm{MeOH}$ - which is quenched at low temperatures. A reason for the different behavior of the two solvents will be given below.
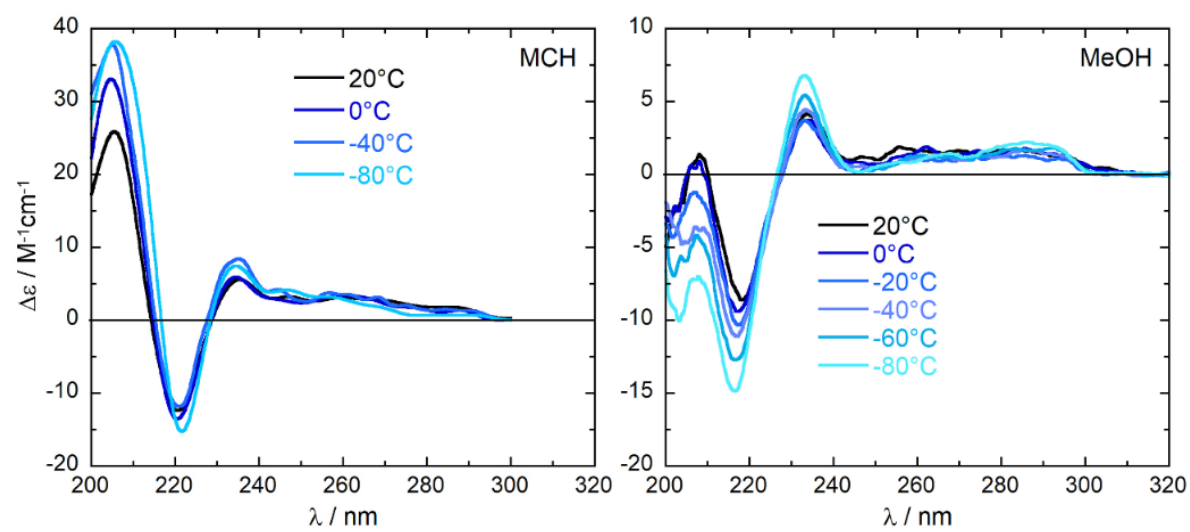

Figure 3. ECD spectra of (R)-tolterodine (1) measured in $\mathrm{MCH}$ and $\mathrm{MeOH}$ at variable temperatures. Concentration $1.67 \times 10^{-4} \mathrm{M}$, cell path length $0.1 \mathrm{~cm}$. 


\subsection{ECD Calculations and AC Assignment}

To simulate the ECD spectrum of tolterodine (1), we used a well-established calculation procedure consisting of the following steps [39,40]: (1) conformational search with molecular mechanics; (2) geometry optimizations with density functional theory (DFT); (3) excited-state calculations on all relevant energy minima with time-dependent DFT (TDDFT); (4) Boltzmann averaging of calculated ECD spectra using DFT internal energies.

A conformational search was run on (R)-1 using a Monte Carlo algorithm and Merck Molecular Force Field (MMFF). Not surprisingly, the number of total conformers was huge: 247 within the pre-selected energy window of $10 \mathrm{kcal} / \mathrm{mol}$, of which 54 within $5 \mathrm{kcal} / \mathrm{mol}, 4$ within $2.5 \mathrm{kcal} / \mathrm{mol}$, and only 2 within $2 \mathrm{kcal} / \mathrm{mol}$. These latter showed an intramolecular $\mathrm{O}-\mathrm{H} \cdots \mathrm{N}$ hydrogen bond defining an 8-membered cycle (see diagram in Figure 4). All 247 MMFF conformers were optimized with DFT at the $\omega$ B97X-D $/ 6-31+G(d)$ level in vacuo, affording 89 optimized structures within $10 \mathrm{kcal} / \mathrm{mol}$, 14 within $5 \mathrm{kcal} / \mathrm{mol}$, and 4 within $2.5 \mathrm{kcal} / \mathrm{mol}$ (displayed in Figure 4). All the first 9 low-energy conformers showed the intramolecular $\mathrm{O}-\mathrm{H} \cdots \mathrm{N}$ hydrogen bond.

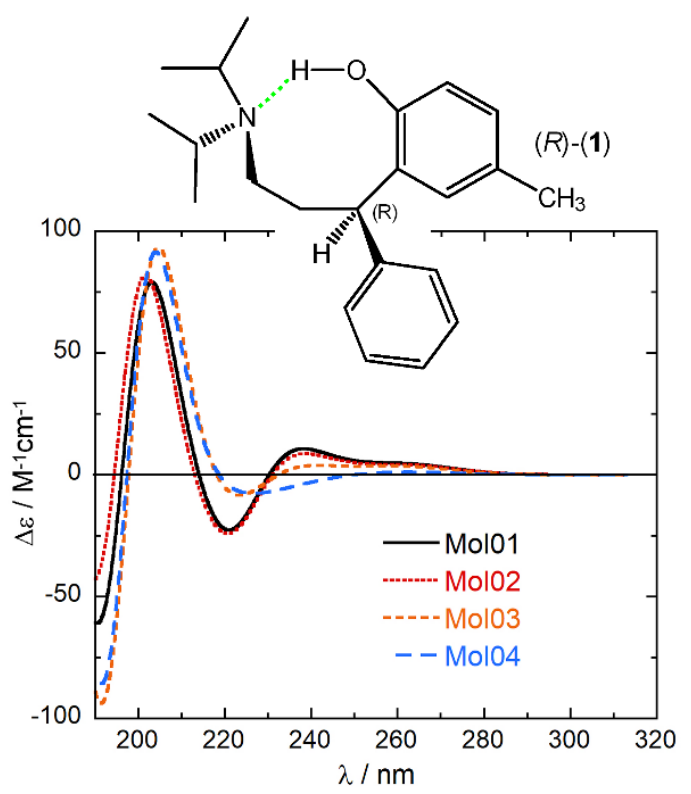

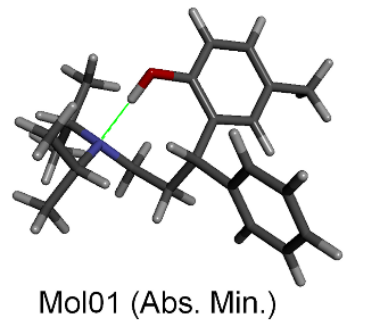

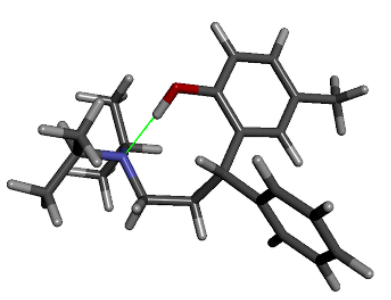

Mol03 (+1.71 kcal/mol)

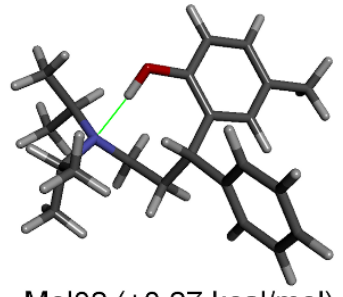

Mol02 (+0.27 kcal $/ \mathrm{mol})$

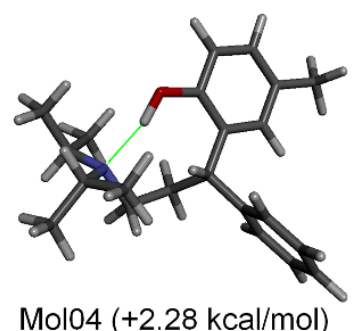

Figure 4. ECD spectra calculated at CAM-B3LYP/def2-TZVP level for the first 4 low-energy conformers of $(R)-\mathbf{1}$ obtained after $\omega$ B97X-D/6-31+G(d) geometry optimizations (shown on the right, with relative energies). Spectra plotted as sum of Gaussians with $\sigma=0.3 \mathrm{eV}$, shifted by $+13 \mathrm{~nm}$. The molecular diagram emphasizes the formation of the intramolecular hydrogen bond (green).

The first four low-energy conformers, covering $98.8 \%$ of the overall Boltzmann population, were considered for ECD simulations. Excited-state calculations were run with B3LYP and CAM-B3LYP functionals and def2-TZVP basis set in vacuo. Since ECD spectroscopy senses the chiral surrounding of the chromophores [38], it was anticipated that the reciprocal orientation of the aromatic rings would determine the ECD response. Such expectation was reinforced by our previous experience with chiral tetraarylmethane [41-43] and diarylmethane [44] derivatives. In the case of $(R)-\mathbf{1}$, however, the intramolecular hydrogen bonding locks the two aromatic rings in a fixed position, as witnessed by the fact that the four low-energy conformers differ only in the conformation of the isopropyl groups. Not surprisingly then, the four calculated ECD spectra are very similar to each other (Figure 4). The resulting Boltzmann-weighted average spectra at $293 \mathrm{~K}$ and $193 \mathrm{~K}$ are compared in Figure 5 with the spectra measured in $\mathrm{MCH}$ at the same temperatures. It is expected that this solvent will not disturb the intramolecular hydrogen bonding, so that our low-energy DFT structures will represent correctly the conformational situation. As discussed above, ECD spectra in $\mathrm{MCH}$ are only slightly 
temperature-dependent, probably because the population of hydrogen-bonded structures is already large at room temperature and cannot be raised much by lowering the temperature. Moreover, solvent field effects on ECD spectra are very small for low-polarity solvents such as $\mathrm{MCH}$ [45], justifying our approach of running ECD calculations in vacuo. An attempt to reproduce the ECD spectra in $\mathrm{H}_{2} \mathrm{O}$ or $\mathrm{MeOH}$ would require an accurate treatment of hydrogen bonding which necessitates the inclusion of explicit solvent molecules [46-49], which is beyond the scope of our study. In fact, the result of VT-ECD experiments in $\mathrm{MeOH}$ suggests a more complicated conformational situation with respect to $\mathrm{MCH}$, probably because of a temperature-dependent competition between solute-solvent hydrogen bonding and intramolecular hydrogen bonding.

The agreement between ECD spectra calculated in vacuo and experimental spectra measured in $\mathrm{MCH}$ is extremely good (Figure 5). The signs of the four bands above $200 \mathrm{~nm}$ are all replicated by the calculations. The wavelength spacing between the bands is also reproduced, with the only exception of ${ }^{1} \mathrm{~L}_{b}$ transitions whose energy is slightly overestimated. This is a well-known pitfall of TDDFT calculations of benzene derivatives [44,50-53]. Anyway, there are no doubts about the absolute configuration of the examined compound, which is certainly $(R)-\mathbf{1}$. The similarity factor (SF) [54] between calculated and experimental spectra at $293 \mathrm{~K}$ is 0.92 and 0.98 for B3LYP and CAM-B3LYP calculations, respectively; for the wrong enantiomer $(S)-\mathbf{1}, \mathrm{SF}$ is $<0.01$ for both functionals. The agreement is practically perfect (Figure 5) if we use for the comparison the spectrum measured in $\mathrm{MCH}$ at $-80^{\circ} \mathrm{C}(193 \mathrm{~K})$, a temperature where only the first 2 DFT-optimized conformers retain an appreciable population. Thus, we confirm the absolute configuration (AC) of tolterodine to be $(R)-(+)-1$. This is the first assignment of the AC of tolterodine based on chiroptical spectroscopies. It is also independent of any chemical correlation with other chiral compounds, whose inconsistencies were mentioned in the Introduction.
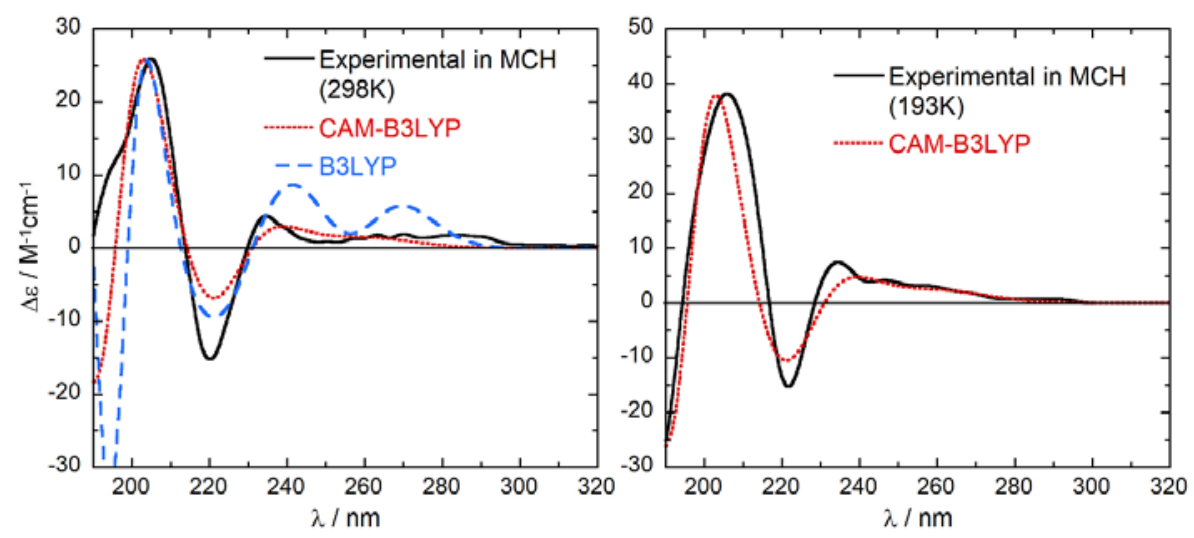

Figure 5. Comparison between experimental ECD spectra of $(R)-\mathbf{1}$ measured in $\mathrm{MCH}$ at $298 \mathrm{~K}$ (left) and $183 \mathrm{~K}$ (right) and ECD spectra calculated at CAM-B3LYP/def2-TZVP and B3LYP/def2-TZVP levels as Boltzmann-weighted averages estimated from $\omega \mathrm{B} 97 \mathrm{X}-\mathrm{D} / 6-31+\mathrm{G}(\mathrm{d})$ energies at the respective temperatures. Spectra plotted as sum of Gaussians with $\sigma=0.3 \mathrm{eV}$, shifted by $+13 \mathrm{~nm}$, scaling factor 0.31 (CAM-B3LYP); $\sigma=0.22 \mathrm{eV}$, shifted by $+6 \mathrm{~nm}$, scaling factor 0.6 (B3LYP).

\subsection{Experimental and Calculated IR/VCD Spectra}

The mid-IR and VCD spectra of (+)-1 measured in $\mathrm{CCl}_{4}$ are reported in Figure 6. This is the best VCD spectrum we were able to obtain after several independent measurements on two different instruments. The VCD spectrum is not particularly weak, as there are several bands with a dissymmetry $g$-factor $(\Delta \varepsilon / \varepsilon)$ above $10^{-4}$. With the help of frequency calculations described below, one may recognize in the IR spectrum the aromatic $C=C$ stretching vibrations around 1600 and $1500 \mathrm{~cm}^{-1}$, the $\mathrm{C}-\mathrm{H}$ bending vibrations of the isopropyl groups at 1400 and $1370 \mathrm{~cm}^{-1}$, the methylene twisting and wagging modes at 1260 and $1250 \mathrm{~cm}^{-1}$, the $\mathrm{C}-\mathrm{N}$ stretching vibrations at 1170 and $1150 \mathrm{~cm}^{-1}$, and the aromatic $\mathrm{C}-\mathrm{H}$ in-plane bending vibrations around $1030 \mathrm{~cm}^{-1}$. Frequency calculations were 
first run on the 4 most stable conformers of $(R)-\mathbf{1}$ described above, after re-optimization at the B3LYP/6-311+G(d,p) level in vacuo. However, the Boltzmann-weighted average calculated VCD spectrum, constructed from DFT-computed internal energies, did not reproduce satisfactorily the experimental spectrum. To exclude the possibility that we missed some important conformers in the calculation, we repeated B3LYP/6-311+G(d,p) geometry optimizations and frequency calculations on the first 40 conformers obtained after the previous $\omega B 97 X-D / 6-31+G(d)$ optimizations. Unfortunately, the conformer populations did not vary too much; the first 4 low-energy conformers still covered a large amount $(89.8 \%)$ of the overall Boltzmann population. In fact, the weighted-average IR and VCD spectra did not differ appreciably from the first result. These final spectra are plotted in Figure 6. The agreement between experimental and calculated IR spectra is not bad, although some experimental IR bands are missing in the calculated spectrum (see asterisks in Figure 6). On the contrary, the agreement between experimental and calculated VCD spectra is poor. Although a few VCD bands are correctly predicted (correspondence highlighted by vertical bars in Figure 6), several moderately strong VCD bands are not reproduced at all by calculations (asterisked in Figure 6).

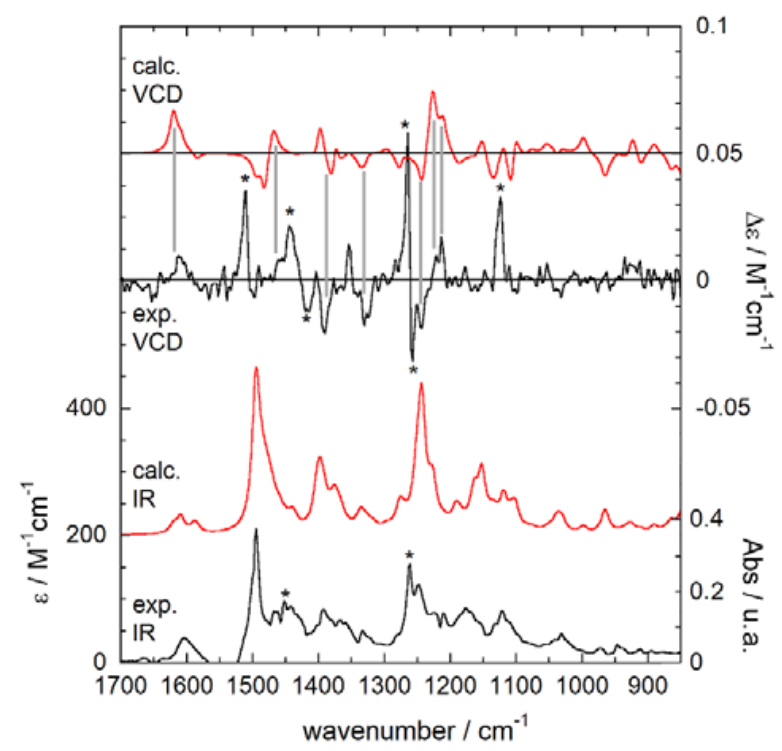

Figure 6. Experimental (black lines) and calculated (red lines) IR (bottom traces) and VCD (top traces) spectra of $(R)$-1. Experimental conditions: $0.18 \mathrm{M}$ solution in $\mathrm{CCl}_{4}$, cell path length $100 \mu \mathrm{m}$. Calculations run at B3LYP / 6-311+G(d,p) level, Boltzmann average over 40 conformers, plotted as sum of Lorentzians with $\gamma=6 \mathrm{~cm}^{-1}$, scaling factor 0.98 . The vertical bands highlight the correspondence between experimental and calculated VCD peaks, while the asterisks $\left(^{*}\right)$ indicate experimental IR/VCD peaks with no calculated counterpart.

Using the best-fitting parameters evaluated from IR spectral comparisons to plot the VCD spectra, we obtained a disappointingly low SF of 0.28 for the correct $(R)$-enantiomer, and a just smaller SF of 0.17 for the wrong $(S)$-enantiomer. The situation was not much better when the Boltzmann averages were constructed from DFT-computed free energies instead of internal energies, which led to a SF of 0.29 for the correct $(R)$ enantiomer, and 0.14 for the wrong $(S)$ enantiomer. It can be concluded that the AC of tolterodine (1) could not be assigned from our VCD study, while ECD results described above were fully satisfactory. The reason for this failure must be probably sought in the possible occurrence of solute aggregation in the chosen solvent $\left(\mathrm{CCl}_{4}\right)$ at the relatively large concentration used for VCD measurements ( 0.18 M, 3 orders of magnitude larger than for ECD) [55]. It must be mentioned that, at the same concentration, tolterodine (1) was sparely soluble in $\mathrm{CDCl}_{3}$ and not soluble in $\mathrm{CD}_{3} \mathrm{CN}$ or $\mathrm{D}_{2} \mathrm{O}$. The occurrence of aggregation is suggested by the already discussed presence of various experimental IR/VCD bands which have no calculated counterpart. A theoretical description of the effects of self-aggregation is possible but beyond the scope of the present manuscript [56,57]. 


\section{Materials and Methods}

\subsection{General Information}

For experimental details on the preparation of $(R)-(+)$-tolterodine $(\mathbf{1})$ and its characterization data, see [32]. ECD/UV spectra were recorded using a J-815 spectrometer (Jasco, Tokyo, Japan) at room temperature in spectroscopic grade solvents. Solutions with suitable concentrations (details are given in the legend of each figure) were measured in quartz cells with a path length of $0.1 \mathrm{~cm}$. All spectra were recorded using a scanning speed of $100 \mathrm{~nm} \mathrm{~min}{ }^{-1}$, a step size of $0.2 \mathrm{~nm}$, a bandwidth of $1 \mathrm{~nm}$, a response time of $0.5 \mathrm{~s}$, and an accumulation of 4 scans. The spectra were background-corrected using the respective solvent spectra recorded under the same conditions. VT-ECD measurements were carried out by using an Optistat optical spectroscopy cryostat (Oxford Instruments, Abingdon, UK) attached to the sample chamber of ECD instrument, in the temperature range from +25 to $-80{ }^{\circ} \mathrm{C}$, using measurement parameters listed above. Baseline correction was done by subtracting the spectrum of a reference solvent obtained under the same conditions; all VT-ECD spectra were normalised using a concentration at $25^{\circ} \mathrm{C}$. VCD/IR spectra were collected using a ChiralIR-2X VCD spectrometer from BioTools Inc. (Jupiter, FL, USA) at a resolution of $4 \mathrm{~cm}^{-1}$ in the range of $2000-850 \mathrm{~cm}^{-1}$ in spectroscopic grade $\mathrm{CCl}_{4}$ for $6 \mathrm{~h}$. The spectrometer was equipped with dual sources and dual $\mathrm{ZnSe}$ photoelastic modulators (PEMs) optimized at $1400 \mathrm{~cm}^{-1}$. A solution was measured in a $\mathrm{BaF}_{2}$ cell with a path length of $\sim 100 \mu \mathrm{m}$ assembled in a rotating holder. Baseline correction was achieved by subtracting the spectrum of $\mathrm{CCl}_{4}$ recorded under the same conditions.

\subsection{Computational Section}

Conformational searches and preliminary DFT calculations were run with Spartan'16 (2017, Wavefunction, Irvine, CA, USA) using default grids and convergence criteria. DFT and TDDFT calculations were run with the Gaussian16 suite [58], using default grids and convergence criteria. A conformational search was run on (R)-1 with molecular mechanics (Merck Molecular Force Field, MMFF) using the Monte Carlo algorithm implemented in Spartan'16, allowing all possible rotations around single bonds. All structures thus found were optimized with DFT at the $\omega B 97 X-D / 6-31+G(d)$ level in vacuo in Spartan'16. Further optimizations and frequency calculations were run in Gaussian at B3LYP/6-311+G(d,p) level in vacuo. All relevant structures had zero imaginary frequencies. TDDFT calculations were run on $\omega$ B97X-D/6-31+G(d) optimized structures with both B3LYP and CAM-B3LYP functionals, and the def2-TZVP basis set. The calculations included 40 excited states (roots). Component spectra were averaged according to the Boltzmann distribution at 293 and $193 \mathrm{~K}$ using the populations estimated from internal and free energies. All spectra were averaged and plotted using the software SpecDis (v 1.71) [54,59] using the plotting parameters listed in the figure legends. SpecDis was also employed to estimate similarity factors (SF).

\section{Conclusions}

The most important conclusion of our study is the assignment of the AC of tolterodine as $(R)-(+)-\mathbf{1}$. This confirms the previous X-ray assignment of the hydrogen L-tartrate salt [16], which should be quoted as the only reliable reference for the AC of the title compound. On the contrary, the patents by Jönsson [5] and Gage and Cabaj [15] contain no proof of the claimed AC, while the patent by Piccolo et al. [21] reports a chemical correlation with 6-methyl-4-phenylchroman-2-one (3) whose AC is unsure. Several subsequent enantioselective syntheses are also based on the same intermediate, whose literature OR data are ambiguous. Our study offers the first assignment of the AC of tolterodine based on chiroptical spectroscopies, which is independent of any chemical correlation with other chiral compounds. Our assignment is based on the comparison between experimental ECD spectra, measured in different solvents and at variable temperatures, with TDDFT-calculated spectra, whose agreement was excellent. On the contrary, experimental VCD spectra were not reproduced by DFT calculations, possibly because of solute aggregation affecting experimental spectra. 
It is also worth mentioning that our literature survey did not highlight the existence of a definite proof of the enantioselective mode of action of tolterodine. In the original patent, both calcium antagonistic and anticholinergic effects, as well as toxicity, were reported to be similar for the enantiomerically pure compound and the racemic one. Almost all subsequent studies concerned the drug only in its enantiomerically pure form, with no further evidence of its superiority over the racemate. Because of the importance of this drug, several enantioselective syntheses and enantiomer separations have been reported in years. However, further clinical data need be acquired to demonstrate the necessity of pursuing and using the drug in its enantiomerically pure form.

Author Contributions: Conceptualization, G.P. and A.I.; investigation, M.G., V.Z., A.I. and G.P.; writing-original draft preparation, G.P.; writing—review and editing, M.G., A.I and G.P.; visualization, G.P. and M.G.

Funding: This research received no external funding.

Acknowledgments: We acknowledge the CINECA award under the ISCRA initiative for the availability of high-performance computing resources and support.

Conflicts of Interest: The authors declare no conflict of interest.

\section{References and Note}

1. Ananchenko, G.; Novakovic, J. Tolterodine Tartrate. In Profiles of Drug Substances, Excipients and Related Methodology; Brittain, H.G., Ed.; Academic Press: Cambridge, MA, USA, 2017; Volume 42, pp. 339-403.

2. Hills, C.J.; Winter, S.A.; Balfour, J.A. Tolterodine. Drugs 1998, 55, 813-820. [CrossRef]

3. Appell, R.A. Clinical efficacy and safety of tolterodine in the treatment of overactive bladder: A pooled analysis. Urology 1997, 50, 90-96. [CrossRef]

4. Chiral Drugs: Chemistry and Biological Action; Lin, G.-Q.; You, Q.-D.; Cheng, J.-F. (Eds.) Wiley: Hoboken, NJ, USA, 2011.

5. Jönsson, N.A.; Sparf, B.A.; Mikiver, L.; Moses, P.; Nilvebrant, L.; Glas, G. New Amines, Their Use and Preparation. EP0325571B1, 22 January 1988.

6. Detrol (tolterodine L-tartrate) Tablets. Available online: https://www.accessdata.fda.gov/drugsatfda_docs/ nda/98/20771_Detrol.cfm (accessed on 24 January 2019).

7. Stahl, M.M.S.; Ekström, B.; Sparf, B.; Mattiasson, A.; Andersson, K.-E. Urodynamic and other effects of tolterodine: A novel antimuscarinic drug for the treatment of detrusor overactivity. Neurourol. Urodyn. 1995, 14, 647-655. [CrossRef] [PubMed]

8. Nilvebrant, L.; Hallén, B.; Larsson, G. Tolterodine-a new bladder selective muscarinic receptor antagonist: Preclinical pharmacological and clinical data. Life Sci. 1997, 60, 1129-1136. [CrossRef]

9. Alberg, G. S(-)-tolterodine in the treatment of Urinary and Gastrointestinal Disorders. U.S. Patent 6310103B1, 19 July 1996.

10. Novotna, A.; Kamenickova, A.; Pecova, M.; Korhonova, M.; Bartonkova, I.; Dvorak, Z. Profiling of enantiopure drugs towards aryl hydrocarbon (AhR), glucocorticoid (GR) and pregnane X (PXR) receptors in human reporter cell lines. Chem. Biol. Interact. 2014, 208, 64-76. [CrossRef] [PubMed]

11. Doricakova, A.; Theile, D.; Weiss, J.; Vrzal, R. Differential effects of the enantiomers of tamsulosin and tolterodine on P-glycoprotein and cytochrome P450 3A4. Naunyn Schmiedebergs Arch. Pharmacol. 2017, 390, 49-59. [CrossRef]

12. Krasulova, K.; Siller, M.; Holas, O.; Dvorak, Z.; Anzenbacher, P. Enantiospecific effects of chiral drugs on cytochrome P450 inhibition in vitro. Xenobiotica 2016, 46, 315-324. [CrossRef]

13. Dakarapu, V.V.; Allaka, T.R.; Uppalla, L.K.; Tha, A. Design, Synthesis, and Molecular Modeling of Asymmetric Tolterodine Derivatives as Anticancer Agents. J. Heterocycl. Chem. 2018, 55, 2157-2167. [CrossRef]

14. Gupta, S.; Sathyan, G.; Mori, T. New perspectives on the overactive bladder: Pharmokinetics and bioavailability11Suneel Gupta, Gayatri Sathyan, and Timothy Mori hold stock in Johnson \& Johnson and the ALZA Corporation. Urology 2002, 60, 78-80. [CrossRef]

15. Gage, J.R.; Cabaj, J.E. Process to Prepare Tolterodine. U.S. Patent 5,922,914A, 31 December 1996.

16. Košutić-Hulita, N.; Žegarac, M. Tolterodinium (+)-(2R,3R)-hydrogen tartrate. Acta Crystallogr. Sect. C 2005, 61, o171-o173. [CrossRef] [PubMed] 
17. Cianci, M.; Helliwell, J.R.; Helliwell, M.; Kaucic, V.; Logar, N.Z.; Mali, G.; Tusar, N.N. Anomalous scattering in structural chemistry and biology. Crystallogr. Rev. 2005, 11, 245-335. [CrossRef]

18. Smith, G.; Wermuth, U.D.; White, J.M. Proton-transfer and non-transfer in compounds of quinoline and quinaldic acid with L-tartaric acid. Acta Crystallogr. Sect. C Cryst. Struct. Commun. 2006, 62, o694-o698. [CrossRef] [PubMed]

19. Ünal, A.; Şentürk, S.; Şenyel, M. Vibrational spectroscopic and thermal studies of some 3-phenylpropylamine complexes. Vib. Spectrosc 2009, 51, 299-307. [CrossRef]

20. Osborne, R.; Clarke, N.; Glossop, P.; Kenyon, A.; Liu, H.; Patel, S.; Summerhill, S.; Jones, L.H. Efficient conversion of a nonselective norepinephrin reuptake inhibitor into a dual muscarinic antagonist- $\beta_{2}$-agonist for the treatment of chronic obstructive pulmonary disease. J. Med. Chem. 2011, 54, 6998-7002. [CrossRef] [PubMed]

21. Piccolo, O.; Ulgheri, F.; Marchetti, M. Enantioslective Synthesis of Enantiomerically Enriched Compounds. WO2005005356A2, 2 July 2003.

22. Ulgheri, F.; Marchetti, M.; Piccolo, O. Enantioselective Synthesis of (S)- and (R)-Tolterodine by Asymmetric Hydrogenation of a Coumarin Derivative Obtained by a Heck Reaction. J. Org. Chem. 2007, 72, 6056-6059. [CrossRef] [PubMed]

23. Chen, G.; Tokunaga, N.; Hayashi, T. Rhodium-Catalyzed Asymmetric 1,4-Addition of Arylboronic Acids to Coumarins: Asymmetric Synthesis of (R)-Tolterodine. Org. Lett. 2005, 7, 2285-2288. [CrossRef] [PubMed]

24. Hedberg, C.; Andersson, P.G. Catalytic Asymmetric Total Synthesis of the Muscarinic Receptor Antagonist (R)-Tolterodine. Adv. Synth. Catal. 2005, 347, 662-666. [CrossRef]

25. Kobayashi, K.; Nishikata, T.; Yamamoto, Y.; Miyaura, N. Stepwise Palladium-Catalyzed 1,4-Addition of Arylboronic Acids to Enones and Regioselective Baeyer-Villiger Oxidation for Enantioselective Synthesis of $\beta$-Diaryl Esters and (+)-(R)-Tolterodine. Bull. Chem. Soc. Jpn. 2008, 81, 1019-1025. [CrossRef]

26. Gallagher, B.D.; Taft, B.R.; Lipshutz, B.H. Asymmetric Conjugate Reductions of Coumarins. A New Route to Tolterodine and Related Coumarin Derivatives. Org. Lett. 2009, 11, 5374-5377. [CrossRef]

27. Korenaga, T.; Maenishi, R.; Osaki, K.; Sakai, T. Highly active rhodium catalyst with electron-poor diphosphine enables efficient synthesis of chiral 4-aryl- $\delta$-lactones. Heterocycles 2010, 80, 157-162. [CrossRef]

28. Kim, H.; Yun, J. Copper-Catalyzed Asymmetric 1,4-Hydroboration of Coumarins with Pinacolborane: Asymmetric Synthesis of Dihydrocoumarins. Adv. Synth. Catal. 2010, 352, 1881-1885. [CrossRef]

29. Luo, Y.; Carnell, A.J. Chemoenzymatic Synthesis and Application of Bicyclo[2.2.2]octadiene Ligands: Increased Efficiency in Rhodium-Catalyzed Asymmetric Conjugate Additions by Electronic Tuning. Angew. Chem. Int. Ed. 2010, 49, 2750-2754. [CrossRef] [PubMed]

30. Kirkpatrick, D.; Fain, M.; Yang, J.; Trehy, M. Enantiomeric impurity analysis using circular dichroism spectroscopy with United States Pharmacopeia liquid chromatographic methods. J. Pharmacol. Biomed. Anal. 2018, 156, 366-371. [CrossRef] [PubMed]

31. The original paper only contains a single CD value at $231 \mathrm{~nm}$. The full ECD spectrum was kindly made available to us by the authors.

32. Zullo, V.; Iuliano, A. Rh-catalyzed enantioselective conjugate addition of arylboronic acids to 3-arylpropenoates: Enantioselective synthesis of (R)-Tolterodine. Eur. J. Org. Chem. 2018, in press. [CrossRef]

33. Jaffé, H.H.; Orchin, M. Theory and Applications of Ultraviolet Spectroscopy; Wiley: New York, NY, USA, 1962.

34. Herzberg, G. Molecular Spectra and Molecular Structure. III. Electronic Spectra and Electronic Structure of Polyatomic Molecules; D. Van Nostrand Co.: Princeton, NJ, USA, 1966.

35. Doub, L.; Vandenbelt, J.M. The Ultraviolet Absorption Spectra of Simple Unsaturated Compounds. I. Monoand p-Disubstituted Benzene Derivatives. J. Am. Chem. Soc. 1947, 69, 2714-2723. [CrossRef]

36. Dearden, J.C.; Forbes, W.F. Light Absoprtion Studies: Part XIV. The Ultraviolet Absoprtion Spectra of Phenols. Can. J. Chem. 1959, 37, 1294-1304. [CrossRef]

37. Berova, N.; Di Bari, L.; Pescitelli, G. Application of electronic circular dichroism in configurational and conformational analysis of organic compounds. Chem. Soc. Rev. 2007, 36, 914-931. [CrossRef] [PubMed]

38. Pescitelli, G.; Di Bari, L.; Berova, N. Conformational Aspects in the Studies of Organic Compounds by Electronic Circular Dichroism. Chem. Soc. Rev. 2011, 40, 4603-4625. [CrossRef]

39. Pescitelli, G.; Bruhn, T. Good Computational Practice in the Assignment of Absolute Configurations by TDDFT Calculations of ECD Spectra. Chirality 2016, 28, 466-474. [CrossRef] 
40. Superchi, S.; Scafato, P.; Górecki, M.; Pescitelli, G. Absolute Configuration Determination by Quantum Mechanical Calculation of Chiroptical Spectra: Basics and Applications to Fungal Metabolites. Curr. Med. Chem. 2018, 25, 287-320. [CrossRef]

41. Matsumoto, K.; Miki, K.; Inagaki, T.; Nehira, T.; Pescitelli, G.; Hirao, Y.; Kurata, H.; Kawase, T.; Kubo, T. "Marking" the nitrogen atoms of phenyl-(2-pyridyl)-(3-pyridyl)-(4-pyridyl)-methane. Synthesis and absolute configuration of the corresponding tris(pyridine N-oxide). Chirality 2011, 23, 543-548. [CrossRef]

42. Matsumoto, K.; Miki, K.; Kurata, H.; Rikitake, N.; Nehira, T.; Inagaki, T.; Pescitelli, G.; Hirao, Y.; Kawase, T.; Oda, M.; et al. Chiral Tetrakis(2-thienyl)methane Derivative: A Possible Precursor for Cryptochiral Tetraalkylmethanes. Chem. Lett. 2008, 37, 1236-1237. [CrossRef]

43. Matsumoto, K.; Inagaki, T.; Nehira, T.; Kannami, M.; Inokuchi, D.; Kurata, H.; Kawase, T.; Pescitelli, G.; Oda, M. Phenyl-(2-pyridyl)-(3-pyridyl)-(4-pyridyl)methane: Synthesis, chiroptical properties, and theoretical calculation of its absolute configuration. Chem. As. J. 2007, 2, 1031-1036. [CrossRef] [PubMed]

44. Padula, D.; Pescitelli, G. How and how much molecular conformation affects electronic circular dichroism: The case of 1,1-diarylcarbinols. Molecules 2018, 23, 128. [CrossRef] [PubMed]

45. Mennucci, B.; Cappelli, C.; Cammi, R.; Tomasi, J. Modeling solvent effects on chiroptical properties. Chirality 2011, 23, 717-729. [CrossRef] [PubMed]

46. Štěpánek, P.; Bouř, P. Multi-scale modeling of electronic spectra of three aromatic amino acids: Importance of conformational averaging and explicit solute-solvent interactions. Phys. Chem. Chem. Phys. 2014, 16, 20639-20649. [CrossRef]

47. Pikulska, A.; Hopmann, K.H.; Bloino, J.; Pecul, M. Circular Dichroism and Optical Rotation of Lactamide and 2-Aminopropanol in Aqueous Solution. J. Phys. Chem. B 2013, 117, 5136-5147. [CrossRef] [PubMed]

48. Mazzeo, G.; Santoro, E.; Andolfi, A.; Cimmino, A.; Troselj, P.; Petrovic, A.G.; Superchi, S.; Evidente, A.; Berova, N. Absolute Configurations of Fungal and Plant Metabolites by Chiroptical Methods. ORD, ECD, and VCD Studies on Phyllostin, Scytolide, and Oxysporone. J. Nat. Prod. 2013, 76, 588-599. [CrossRef]

49. Cappelli, C.; Bronco, S.; Monti, S. Computational study of conformational and chiroptical properties of

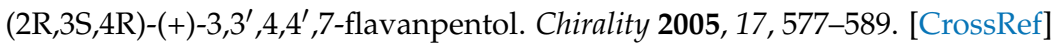

50. Parac, M.; Grimme, S. A TDDFT study of the lowest excitation energies of polycyclic aromatic hydrocarbons. Chem. Phys. 2003, 292, 11-21. [CrossRef]

51. Pescitelli, G.; Barone, V.; Di Bari, L.; Rizzo, A.; Santoro, F. Vibronic Coupling Dominates the Electronic Circular Dichroism of the Benzene Chromophore L-1(b) band. J. Org. Chem. 2013, 78, 7398-7405. [CrossRef]

52. Pescitelli, G.; Di Bari, L.; Caporusso, A.M.; Salvadori, P. The prediction of the circular dichroism of the benzene chromophore: TDDFT calculations and sector rules. Chirality 2008, 20, 393-399. [CrossRef] [PubMed]

53. Rode, J.E.; Górecki, M.; Witkowski, S.; Frelek, J. Solvation of 2-(hydroxymethyl)-2,5,7,8-tetramethyl-chroman6-ol revealed by circular dichroism: A case of chromane helicity rule breaking. Phys. Chem. Chem. Phys. 2018, 20, 22525-22536. [CrossRef] [PubMed]

54. Bruhn, T.; Schaumlöffel, A.; Hemberger, Y.; Bringmann, G. SpecDis: Quantifying the Comparison of Calculated and Experimental Electronic Circular Dichroism Spectra. Chirality 2013, 25, 243-249. [CrossRef] [PubMed]

55. Merten, C. Vibrational optical activity as probe for intermolecular interactions. Phys. Chem. Chem. Phys. 2017, 19, 18803-18812. [CrossRef] [PubMed]

56. Merten, C.; Amkreutz, M.; Hartwig, A. Determining the structure of $\alpha$-phenylethyl isocyanide in chloroform by VCD spectroscopy and DFT calculations—simple case or challenge? Phys. Chem. Chem. Phys. 2010, 12, 11635-11641. [CrossRef] [PubMed]

57. Bünnemann, K.; Merten, C. Solvation of a chiral carboxylic acid: Effects of hydrogen bonding on the IR and VCD spectra of $\alpha$-methoxyphenylacetic acid. Phys. Chem. Chem. Phys. 2017, 19, 18948-18956. [CrossRef] [PubMed]

58. Frisch, M.J.; Trucks, G.W.; Schlegel, H.B.; Scuseria, G.E.; Robb, M.A.; Cheeseman, J.R.; Scalmani, G.; Barone, V.; Petersson, G.A.; Nakatsuji, H.; et al. Gaussian 16, Revision A.03; Gaussian, Inc.: Wallingford, CT, USA, 2016.

59. Bruhn, T.; Schaumlöffel, A.; Hemberger, Y.; Pescitelli, G. SpecDis Version 1.71; Berlin, Germany, 2017. Available online: https:/ / specdis-software.jimdo.com/ (accessed on 24 January 2019).

(C) 2019 by the authors. Licensee MDPI, Basel, Switzerland. This article is an open access article distributed under the terms and conditions of the Creative Commons Attribution (CC BY) license (http:/ / creativecommons.org/licenses/by/4.0/). 